\title{
Effects of Commercially Available Whitening Creams on the Epidermal Thickness of Guinea Pig Skin
}

\author{
Sadia Saqib, Rafeea Tafweez, Nadia Haq and Mah-Jabeen Muneera \\ Department of Anatomy, King Edward Medical University, Lahore, Pakistan
}

\begin{abstract}
Objective: To determine the effects of commonly used commercial skin lightening creams on the thickness of epidermis of guinea pig skin.

Study Design: Animal experimental study.

Place and Duration of Study: Department of Anatomy, King Edward Medical University, Lahore, from March to May 2015. Methodology: Forty-eight adult, colored guinea pigs were used in this study. The animals were randomly divided into four groups. Group I was control group (no cream application). The animals of group II, III and IV were treated with skin whitening creams A, B and C respectively once daily, 6 days/week for eight weeks duration. The observations of skin specimens were made after 4 and 8 weeks for epidermal thickness at histological level.

Results: Microscopic examination showed variable degrees of epidermal thickening with the three creams applied for 4 weeks. The increase in thickness of epidermis ranged from $49.1 \mu \mathrm{m}$ in control group to maximum of $106.4 \mu \mathrm{m}$ in group II. These effects were further intensified after 8 weeks application.

Conclusion: The use of whitening creams caused skin damage by increasing the epidermal thickness of varying extent.
\end{abstract}

Key Words: Skin whitening creams, Guinea pig skin, Epidermal thickening.

How to cite this article: Saqib S, Tafweez R, Haq N, Muneera M. Effects of commercially available whitening creams on the epidermal thickness of guinea pig skin. J Coll Physicians Surg Pak 2019; 29(9):799-802.

\section{INTRODUCTION}

To have an attractive skin complexion is a desire of every person, especially young females. Application of various household products, herbs and chemicals for achieving the goal has been in practice since ages. ${ }^{1}$ The use of whitening creams is more common in tropical areas of the world, 2 including Pakistan.

Seventy-seven percent of the Nigerian women use skin lightening products, according to World Health Organization. This is the highest percentage in the world. ${ }^{3}$ Similarly, $59 \%$ women in Togo and $27 \%$ women in Senegal also use skin whitening creams. ${ }^{4}$

Most skin whitening creams contain ingredients as hydroquinone, corticosteroids, and mercury. ${ }^{5}$ Mechanism of action of most of these ingredients is direct inhibition of enzyme tyrosinase and related melanogenic enzymes. ${ }^{6}$ Skin bleaching agents have both external and internal effects. The effects on the skin can be redness, severe irritation, eczema, decrease in skin thickness, blotchy appearance due to uneven color loss, ochronosis and skin cancers. ${ }^{7}$ Pale skinned people are roughly thousand times more likely to suffer from skin cancers. ${ }^{2}$

Correspondence to: Dr. Sadia Saqib, Department of Anatomy,

King Edward Medical University, Lahore, Pakistan

E-mail: sadia_saqib@hotmail.com

Received: September 18, 2018; Revised: April 24, 2019;

Accepted: May 20, 2019
The internal effects noted with the use of bleaching creams, containing harmful chemicals, include cancers e.g. leukemia, carcinoma of liver and kidney failure. 8 There is also increased predisposition of infections and suppression of hypothalamic pituitary adrenal axis due to the use of corticosteroids. ${ }^{5,9}$

Depending upon the anatomical site and influence of the environment, there is a remarkable diversity in the structure of skin. The skin is composed of epidermis and dermis. The epidermis consists of stratified squamous keratinized epithelium composed of cells called keratinocytes. ${ }^{10}$ There is no statistical data available from Pakistan regarding the percentage of population using these skin whitening creams though similar or even higher trend is expected in our part of the world because of general preference for fair complexion to the extent of development of social pressure. Easy availability of skin whitening creams in local markets at low price becomes an additional promoting factor for use of such products.

In general, the guinea pig is a good model of human skin for in vitro permeability experiments. ${ }^{11}$ So, this study was conducted to determine the effects of commonly used commercial skin lightening creams on guinea pig skin and to highlight the importance of population awareness and information brochure in the use of non-prescription skin whitening creams.

\section{METHODOLOGY}

This experimental study was conducted at Department of Anatomy, King Edward Medical University, Lahore, 
from March to May 2015. Forty-eight adult guinea pigs of weight 500-1000 gms and having mixed skin color were kept in the animal house and acclimatised for 15 days. A 12-hour light and dark cycle was maintained at room temperature between $22-25^{\circ} \mathrm{C}$. Food and water was provided to these animals ad-libitum. The food given was in the form of grass hey and chick peas.

Animals were randomly divided into 4 groups: one control and 3 experimental groups. There were 12 animals in each group. All the animals were further divided into subgroups as la and $\mathrm{lb}$ having six animals in each subgroup. The animals in subgroups were marked by colour coding for identification.

A survey was done in three known markets of Lahore. Some busy shops of cosmetics were surveyed and three most commonly sold whitening creams were chosen for the experiment. These were labelled as A, B and C.

An area of skin of animals measuring $3 \times 2 \mathrm{~cm}$ approximately on the dorsum at maximum convexity of vertebral column was cleaned and shaved. Small pea-sized $(0.25$ $\mathrm{gm}$ ) cream was taken for each animal and was gently spread on the shaved area in all experimental groups once daily, 6 days/week.

After 4 weeks duration, 6 animals from subgroup "a" of all groups were separated. After anesthesia with chloroform, an elliptical skin from the treated area was dissected and a skin specimen was taken. The margins of remaining skin were approximated and stitched with the silk suture. The specimen of skin obtained was kept in $10 \%$ formalin solution in labelled plastic jars.

The animals of subgroup "b" were applied with the same cream in the same pattern for 4 more weeks. At the end of 8 weeks duration, similar procedure was done for collection and preservation of samples for histological examination.

The fixed skin specimens were placed in individual plastic cassettes, labelled and processed in automatic tissue processor (Histotech III USA). In the processor, the tissue went through dehydration, removal of fixative, clearing and paraffin infiltration. Tissue blocks were prepared. Sectioning was done by using Histoline RM 2258 rotary microtome, dewaxed and stained with hematoxylin \& eosin.13 Sections that were true representative of the findings of specific group were selected. Light microscopy was done. Photomicrograph was taken using camera Nikon DS-Ri2 attached with Nikon Eclipse Ci microscope. The image on microscope was focused with 40X objective and power of eyepiece being 10X, giving a magnification of 400X.
After calibration for micrometry, average thickness of epidermis was measured in each slide at truly representative three points $(X, Y, Z)$. Each measurement was taken from the surface of epidermis to the maximum height of dermal papillae. Average of these readings was taken as thickness of epidermis in that slide.

\section{RESULTS}

Animals of group I were control so the skin of their dorsum was shaved but nothing was applied on it throughout the experimental period. Observations were made at 4 and 8 weeks. The mean thickness of the epidermis was $49.2 \pm 2 \mu \mathrm{m}$ and it was consisting of several layers of cells (Table I, Figure 1).

Cream A was applied to experimental group Ila animals for 4 weeks. On histological examination, the epidermis seemed very thick. Mean epidermal thickness was 106.4 $\pm 8 \mu \mathrm{m}$, showing thickness of all the strata of epidermis; but no distinction of cell types was made (Table I).

Cream A was applied to experimental subgroup IIb for 8 weeks duration. Epidermis appeared very thick in comparison to control. Mean epidermal thickness was $107.2 \pm 12.6 \mu \mathrm{m}$ which turned out to be thickest of all the experimental group animals (Table I, Figure 2).

Cream B was applied to experimental subgroup IIla for 4 weeks. On histological examination, the epidermis was thickened out in this animal group when compared with the control with the mean value of $105.1 \pm 5.3 \mu \mathrm{m}$ (Table I). Cream B was applied to animals of subgroup IIlb for 8 weeks duration. On histological examination, mean epidermal thickness was $106 \pm 14.7 \mu \mathrm{m}$ (Table I, Figure 3).

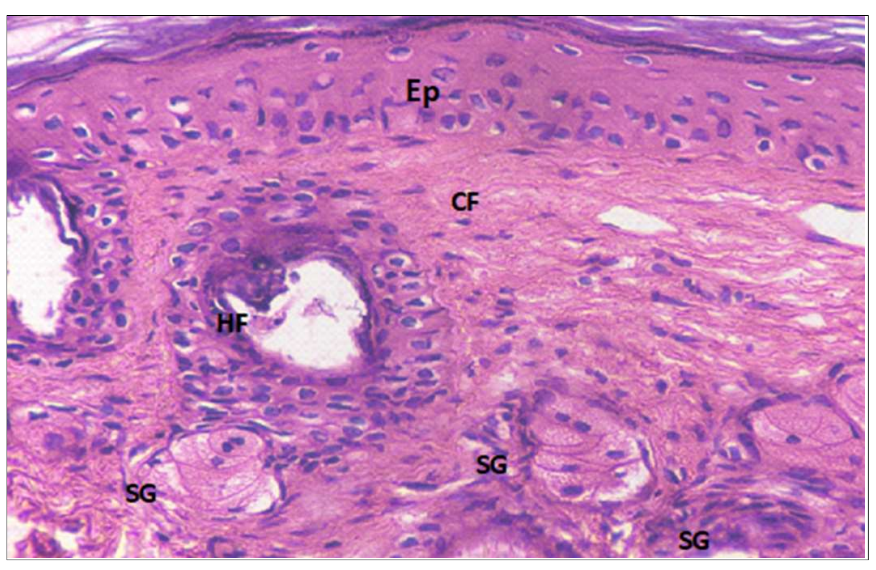

Figure 1: Photomicrograph of control group (I) animal showing normal looking epidermis (Ep). Papillary dermis showing normal distribution of collagen fibers (CF). Reticular dermis showing normal hair follicles (HF) and sebaceous glands (SG). (H\&E) magnification $40 \mathrm{X} \times 10 \mathrm{X}=400 \mathrm{X}$.

Table I: Comparison among groups for thickness of epidermis.

\begin{tabular}{l|c|c|c|c}
\hline \multirow{2}{*}{ Group } & \multicolumn{2}{|c|}{ Thickness of epidermis at 4th week $(\mu \mathrm{m})$} & \multicolumn{2}{|c}{ Thickness of epidermis at 8th week $(\mu \mathrm{m})$} \\
\cline { 2 - 5 } & Mean & Standard Deviation & 49.2 & Mean \\
\hline Group I & 49.1 & 1.5 & 107.2 & 2.0 \\
\hline Group II & 106.4 & 8.0 & 106.0 & 12.6 \\
\hline Group III & 105.1 & 5.3 & 71.6 & 14.7 \\
\hline Group IV & 72.5 & 5.4 & 0.910 & \\
\hline
\end{tabular}

Group I Control group. Group II Experimental group treated with cream A, Group II Experimental group treated with cream B. Group IV Experimental group treated with cream C. 


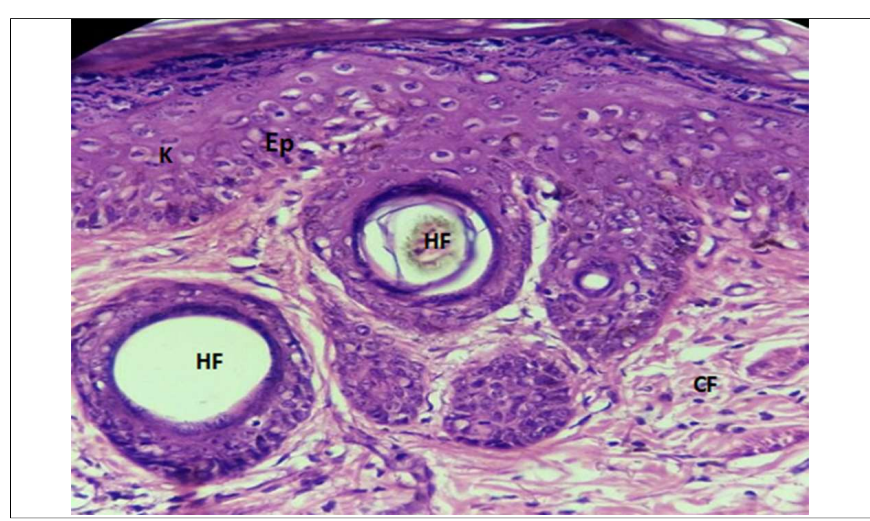

Figure 2: Photomicrograph of group II showing thickened epidermis (Ep) with multiple layers of keratinocytes $(\mathrm{K})$. In papillary dermis fine network of collagen fibers (CF) are visible. Enlarged hair follicles (HF) are visible in reticular dermis. (H\&E) magnification $40 \mathrm{X} \times 10 \mathrm{X}=400 \mathrm{X}$.

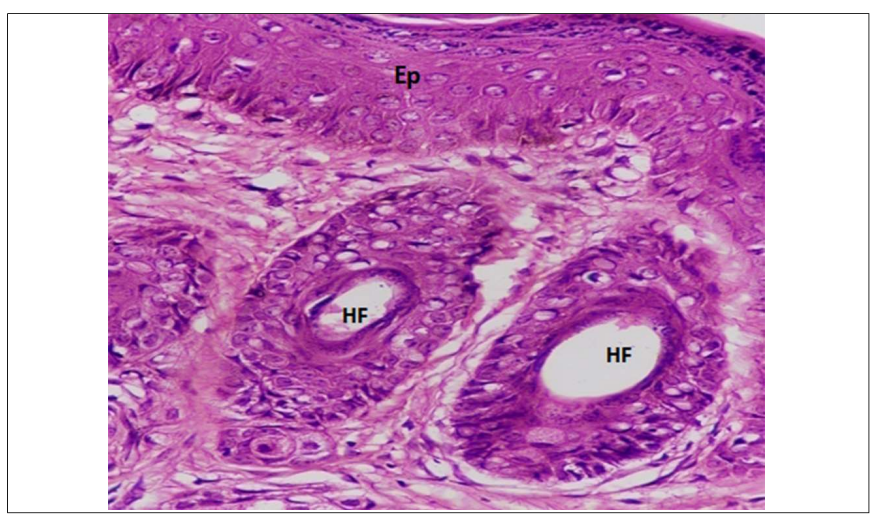

Figure 3: Photomicrograph of group III showing thickened epidermis and markedly enlarged hair follicles (HF) present in reticular dermis. Dense collagen fiber bundles are visible around hair follicles. (H\&E) magnification $40 \mathrm{X} \times 10 \mathrm{X}=400 \mathrm{X}$.

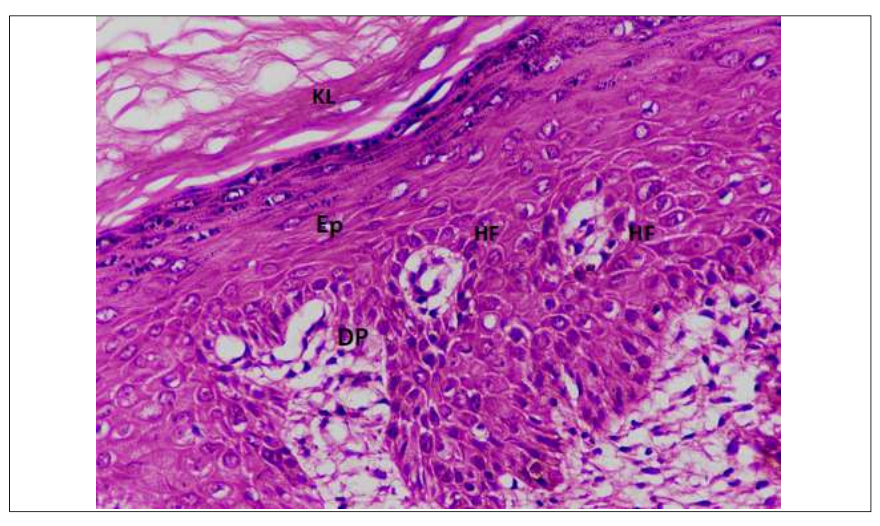

Figure 4: Photomicrograph of group IV showing thickened epidermis (Ep). Prominent keratin layer (KL) and dermal papillae (DP) with hair follicles (HF) are visible. (H\&E) magnification $40 \mathrm{X} \times 10 \mathrm{X}=400 \mathrm{X}$.
Cream C was applied to animals of subgroup IVa for 4 weeks duration. On histological examination, mean epidermal thickness of $72.5 \pm 5.4 \mu \mathrm{m}$ (Table I). Cream C was applied to experimental subgroup IV b for 8 weeks duration. On histological examination, mean epidermal thickness of $71.6 \pm 6.5 \mu \mathrm{m}$ (Table I, Figure 4). It was greater than control group but less as compared to group II and III.

The thickness of epidermis was not significantly different in all 4 groups between 4 and 8 weeks time (Table I). On group-wise comparison, the groups II, III and IV had significantly higher thickness as compared to control group with $p$-values of $0.001,0.001$ and 0.006 , respectively. The increase in epidermal thickness was more marked in group II and III but there is no difference between the two when compared with each other $(p=0.979)$. Group IV had significantly lower epidermal thickness as compared to group II and III $(p=0.001)$. Similar results were observed after 8 weeks' time (Table II).

\section{DISCUSSION}

The chemical composition of most of the available skin lightening products is usually a combination of hydroquinone, corticosteroids, and mercury. ${ }^{14}$ This study was conducted to see the effect of these skin whitening creams on the thickness of epidermis. For this purpose, experiment was performed on the skin of guinea pigs because of their great similarity with the human skin. Epidermal thickness was recorded after a period of 4 weeks and 8 weeks exposure of three different types of commonly available skin whitening creams. An increase in thickness of epidermis was seen in all experimental groups. This effect was similar to the results of a previously conducted study in 2011 by Al-Aqeel et al. in which $4 \%$ hydroquinone was applied on the skin of 30 guinea pigs for 35 days. A notable increase in the epidermal thickness of up to $403.5 \mu \mathrm{m}$ was observed; whereas, epidermal thickness of control group was only $91 \mu \mathrm{m} .{ }^{15}$

Thickness of epidermis was also reported in a study of Farghaly et al., in which effects of three whitening creams was seen on the skin of 15 guinea pigs for a duration of 8 weeks. In this study, along with increase in epidermal thickness, increased proliferation of hair follicles and sebaceous glands and increased elastic fiber deposition was also observed. ${ }^{12}$ Another study conducted by Miao in China observed similar results of increase in epidermal thickness along with decrease in melanin pigment after application of 3\% hydroquinone on guinea pig skin. ${ }^{16}$

Table II: Group-wise comparison of thickness of epidermis among four groups at 4 and 8 weeks (Tukey's test).

\begin{tabular}{|c|c|c|c|c|c|c|c|}
\hline \multirow[t]{2}{*}{ (I) Group } & \multirow[t]{2}{*}{ (J) Group } & \multicolumn{3}{|c|}{$4^{\text {th }}$ week } & \multicolumn{3}{|c|}{$8^{\text {th }}$ week } \\
\hline & & Mean difference (I-J) & Std. Error & $\mathrm{p}$-value & Mean difference $(I-J)$ & Std. Error & $\mathrm{p}$-value \\
\hline \multirow[t]{3}{*}{ Group I } & Group II & $-57.30^{*}$ & 3.21 & 0.001 & $-58.00^{*}$ & 5.91 & 0.001 \\
\hline & Group III & $-56.03^{*}$ & 3.21 & 0.001 & $-56.80^{\star}$ & 5.91 & 0.001 \\
\hline & Group IV & $-23.43^{*}$ & 3.21 & 0.006 & $-22.40^{\star}$ & 5.91 & 0.006 \\
\hline \multirow[t]{2}{*}{ Group II } & Group III & 1.27 & 3.21 & 0.979 & 1.20 & 5.91 & 0.997 \\
\hline & Group IV & $33.87^{*}$ & 3.21 & 0.001 & $35.60^{*}$ & 5.91 & 0.001 \\
\hline Group III & Group IV & $32.60^{\star}$ & 3.21 & 0.001 & $34.40^{*}$ & 5.91 & 0.001 \\
\hline
\end{tabular}

Group I Control group. Group II Experimental group treated with cream A, Group III Experimental group treated with cream B. Group IV Experimental group treated with cream C. 
As corticosteroids are one of the important ingredients of these whitening creams, so common cutaneous complications such as contact dermatitis, facial acne and hypertrichosis have been observed with the use of topical corticosteroids; whereas, their long term use cause thinning or atrophy of skin, an effect contrary to the effects seen in this study. ${ }^{17}$ Similar effects of corticosteroids use were also observed by Al-Dhalami et al. who observed cutaneous atrophy in $17.1 \%$ out of a total of 180 patients after misuse of topical corticosteroids. ${ }^{18}$ Cutaneous atrophy was also seen by Dey et al. in $10 \%$ patients out of a total of 6,723 , who misused topical corticosteroids. ${ }^{19}$ Skin atrophy is induced by chronic topical corticosteroids use rather than by acute treatments. Long-term safety studies may be more relevant to evaluate atrophic activity. 20

The effect observed in present study is similar to the use of whitening creams having hydroquinone as a main ingredient. Thinning of skin is an effect that appears if corticosteroids are applied for a long duration. As this effect is not observed in present study; it means either corticosteroids are not included in their composition or if present, could not cause skin atrophy in this duration of experiment. For this effect to appear, these creams have to be applied for even longer duration. It is also possible that some additional ingredients may be present or the concentration is such that the effects are different.

\section{CONCLUSION}

Commercially available skin whitening creams are harmful for skin because it is observed in this study that they caused skin; damage by causing epidermal hypertrophy of varying degrees.

\section{DISCLOSURE:}

This article is based on one of the author's M. Phil thesis.

\section{CONFLICT OF INTEREST:}

Authors declared no conflict of interest.

\section{AUTHORS' CONTRIBUTION:}

SS: Made substantial contributions to the conception or design, acquisition, analysis, or interpretation of data for the work, drafted the work and revised it critically for important intellectual content; approved the final version to be published; agreed to be accountable for all aspects of the work in ensuring that questions related to the accuracy or integrity of any part of the work are appropriately investigated and resolved.

$\mathrm{RT}$, NH: Planned and designed the work; analysed, or interpreted data for the work; drafted the work or revised it critically for important intellectual content.

MJM: Drafted the work and revised it critically for important intellectual content.

\section{REFERENCES}

1. Radhakrishnan N, Vijayachandra K, Ranganathan S. Changing skin color: Evolution and modern trends. Ind J Dermatol 2007; 52:71-7.

2. Tarlach G. Darker skin evolved to reduce cancer risk. Discover 2014; 11:45-77.

3. Aljazeera. Nigeria's dangerous skin whitening obsession [updated on 2013, cited on 2017]. Available at: http://www.aljazeera.com/ indepth/features/2013/04/20134514845907984.html.

4. Mahé A, Ly F, Aymard G, Dangou JM. Skin diseases associated with the cosmetic use of bleaching products in women from Dakar, Senegal. Br J Dermatol 2003; 148:493-500.

5. Ladizinski B, Mistry N, Kundu RV. Widespread use of toxic skin lightening compounds: Medical and psychosocial aspects. Dermatol Clin 2011; 29:111-23.

6. Ebanks JP, Wickett RR, Boissy RE. Mechanisms regulating skin pigmentation: The rise and fall of complexion coloration. Int J Mol Sci 2009; 10:4066-87.

7. Dadzie OE, Petit A. Skin bleaching: Highlighting the misuse of cutaneous depigmenting agents. J Eur Acad Dermatol Venereol 2009; 23:741-50.

8. Ladizinski B, Mistry N, Kundu RV. Widespread use of toxic skin lightening compounds: Medical and psychosocial aspects. Dermatol Clin 2011; 29:111-23.

9. Olumide YM, Akinkugbe AO, Altraide D, Mohammed T, Ahamefule N, Ayanlowo S, et al. Complications of chronic use of skin lightening cosmetics. Int J Dermatol 2008; 47:344-53.

10. Mescher, Anthony L, Luiz Carlos Uchoa Junqueira. Junqueira's Basic Histology: Text and Atlas. 13 th edition. New York: McGraw Hill Medica; 2013: p.316-8.

11. Understanding Animal Research. Guinea pigs in medical research [updated on 2017, cited on 2017]. Available at: http://www. understandinganimalresearch.org.uk/animals/types-animals.

12. Farghaly EFB. Evaluation of the histological skin changes caused by cosmetic bleaching agents in guinea pigs. Bull Alex Fac Med 2006; 42:289-99.

13. Suvarna KS, Layton C, Bancroft JD, editors. Bancroft's theory and practice of histological techniques E-Book. Elsevier Health Sciences; 2018: p.53-135.

14. Ajose FO. Consequences of skin bleaching in Nigerian men and women. Int J Dermatol 2005; 44:41-3.

15. Al-Aqeel NK, Abdel-Mageed EM. Effects of hydroquinone on epidermal non-keratinocytes. Int J Health Sci (Qassim) 2011; 5:9-11.

16. Miao F, Lei TC, Su MY, Yi WJ, Jiang S, Xu SZ. Decolorization of skin and hair-derived melanin by three ligninolytic enzymes. Zhonghua Yi Xue Za Zhi 2017; 97:3428-31.

17. Coondoo A, Phiske M, Verma S, Lahiri K. Side-effects of topical steroids: A long overdue revisit. Indian Dermatol Online J 2014; 5:416-25.

18. Al-Dhalimi MA, Aljawahiry N. Misuse of topical corticosteroids: A clinical study in Iraqi hospital. East Mediterr Health J 2006; 12:847-52.

19. Dey VK. Misuse of topical corticosteroids: A clinical study of adverse effects. Indian Dermatol Online J 2014; 5:436-40.

20. Barnes L, Kaya G, Rollason V. Topical corticosteroid-induced skin atrophy: A comprehensive review. Drug Saf 2015; 38:493-509. 